\title{
A RECUSA À ESCASSEZ: \\ a universalização da biblioteca escolar e a tensão entre o digital e a Lei de Direitos Autorais
}

\author{
REFUSAL OF SCARCITY: \\ the universal coverage of the school library and the \\ tension between digital and Copyright Law
}

\section{RESUMO}

Benjamin Luiz Franklin ${ }^{1}$

A lei 12.244/10 versa sobre a universalização da biblioteca escolar até 2020 , como previsto originalmente, na época de sua assinatura, em 2010. Na ocasião, a hegemonia da materialidade digital ainda se estabelecia, iniciando seu impacto na sociedade. Atualmente, com a intensificação desse processo, muitos dos objetos digitais, que poderiam incrementar o acervo das bibliotecas escolares e promover a implementação da lei, como livros, vídeos, áudios e músicas, têm sua circulação restrita devido à Lei de Direitos Autorais (LDA), a qual controla juridicamente suas permissões de reprodução. Nesse contexto, este trabalho tem como objetivo evidenciar as possibilidades da materialidade dos objetos digitais na universalização da biblioteca escolar. Essa evidência é metodologicamente construída, inicialmente, por uma revisão bibliográfica, que procura sintetizar e relacionar os conceitos de materialidade digital ao par escassez/abundância, que fundamenta a economia dos objetos digitais e seus dispositivos jurídicos correlatos. Em um segundo momento, procuramos sintetizar os resultados experimentais de dois trabalhos, que se apoiam na discussão estabelecida: o projeto Biblioteca Comum, que implementa Recursos Educacionais Abertos como alternativa no incremento do acervo de bibliotecas escolares, no entorno da Universidade Estadual de Londrina, e a Biblioteca Anônima, que procura analisar um acervo de livros digitalizados por comunidades de usuários na deep web. 0 primeiro projeto, perfeitamente legal e garantido por licenças abertas, evidencia a grande possibilidade de incremento do acervo de bibliotecas escolares, mesmo em ambientes de acesso precário, ou inexistente, à internet. 0 segundo, impossibilitado pela LDA de fazer circular seu acervo, evidencia empiricamente a organização de uma comunidade ativa, empenhada no compartilhamento de livros digitalizados. Concluímos, desta forma, que os esforços promovidos pela Lei 12.244/10 deveriam incluir, em sua atual revisão, a flexibilização da LDA, enquanto uma política pública correlata, no sentido de legalizar as réplicas dos objetos digitais, no contexto da biblioteca escolar, para que se possa incrementar seu acervo e universalizar seus benefícios. Esse conjunto de evidências poderá, quiçá, colaborar no fortalecimento das vozes que lutam pela universalização da biblioteca escolar em um contexto contemporâneo.

Palavras-chave: Lei 12.244/10. Lei de Direitos Autorais. Materialidade digital.

\begin{abstract}
The Brazilian law number 12.244/10 refers to the universal access to school libraries until the year of 2020 , as originally stipulated at the time of its creation. In that occasion, the hegemony of digital materiality was being set out and was introducing its first impacts in society. Nowadays, with the intensification of digital materiality, many of the digital objects that could enhance libraries' collections and allow the law enforcement, such books, audios and videos files, have its flow restricted due to Copy Right Law (LDA), which legally controls reproduction permissions. In this context, this work aims to highlight the possibilities of the materiality of digital objects in the universal access of the school library. This evidence is methodologically built, initially by a bibliographic review, which seeks to synthesize and relate the concepts of digital materiality within the pair scarcity / abundance, which underlies the economy of digital objects and their related legal mechanisms. In a second step, we seek to synthesize the results of two experimental works, which support discussions: the Common Library project, which implements Open Educational Resources as an alternative, without increasing the number of school libraries in surroundings of the State University of Londrina, and the Anonymous Library, which seeks to analyze a collection of books digitized by user communities on the deep web. The first project, perfectly legal and guaranteed by open licenses, shows a great possibility of increasing the collection of school libraries, even in environments with precarious or nonexistent access to the Internet. The second, made impossible by the LDA to circulate its collection, empirically evidence an organization of an active community, committed to sharing digitized books. We concluded that the efforts promoted by Law 12.244 / 10, should include, in its current revision, a flexibilization of the LDA, as a related public policy, to legalize replicas of digital objects, in the context of the school libraries, so that it can increase its collection and universalize its benefits. This set of changes can collaborate in strengthening the voices that fight for the universalization of the school library in a contemporary context.
\end{abstract}

Keywords: Law 12.244 /10. Copyright Law. Digital materiality.

1 Professor do Departamento de Ciência da Informação Universidade Estadual de Londrina, Brasil. ORCID https://orcid.org/00000002-4807-8339. E-mail: belfra@gmail.com 


\section{INTRODUÇÃ̃}

Este trabalho pretende apontar as propriedades de reprodutibilidade técnica dos objetos digitais, como potenciais vetores contribuintes para 0 incremento das bibliotecas escolares no Brasil, motivo que se alinha aos esforços promulgados pela Lei № 12.244 , de 24 de maio de 2010, a qual estabelece que toda escola tenha uma biblioteca até maio de 2020 (BRASIL, 2010). Esta lei foi severamente criticada por não apresentar uma definição clara do que seria uma biblioteca escolar, não apresentar os dispositivos jurídicos de punição das instituições dissonantes, nem indicar quais seriam seus mecanismos de financiamento (ORIÁ, 2017). Dadas essas dificuldades, o Projeto de Lei 9.484/18, 0 qual, no momento da escrita deste trabalho, tramita na Câmara dos Deputados, procura aperfeiçoar a Lei 12.244/10, ofertando uma definição mais clara do que seria a biblioteca escolar, apresentando seus mecanismos de financiamento, além de estender seu prazo de implementação para 2024 (BRASIL, 2018). A ausência de um conjunto de políticas públicas, somada às imensas dificuldades territoriais e orçamentárias, referentes às bibliotecas escolares no Brasil, indica um futuro bastante difícil para a implementação da lei (SILVA, 2019).

A inclinação pela evidenciação, no contexto deste trabalho, segue Hessen (2001), no sentido de admitir a complexidade do tema, que está para além de uma narrativa disciplinar, uma síntese demonstrativa, e de envolver a adesão a valores, quer dizer, um conjunto articulado de conceitos cuja inscrição nos sujeitos encerra sentido em si mesmo, balizando ações éticas, morais e estéticas. Daí a importância da "mostração", a evidenciação de um objeto, a invocação de sua presença. No âmbito deste trabalho, a potencialidade da materialidade dos objetos digitais na implementação da lei 12.244 deverá ser, então, evidenciada experimentalmente para invocar, a posteriori, os poderes demonstrativos correspondentes, necessários a sua compreensão.

A formulação dessa "mostração" seguirá o seguinte percurso metodológico: inicialmente, a partir de uma revisão bibliográfica, sintetizaremos o conceito de "grande fábrica", que articulará a materialidade dos objetos digitais a questões sobre a escassez, enquanto um estatuto fundamental do objeto digital, que fundamenta a produção de circuitos de produção, circulação e consumo, que viabiliza os modelos econômicos dos setores tecnológicos e seus respectivos aparatos jurídicos, destacando a Lei de Direitos Autorais e os modelos de licenciamento encontrados no Software Livre e no Creative Commons. Em um segundo momento, contrastaremos qualitativamente os resultados experimentais parciais de dois trabalhos, balizados nas propriedades de reprodutibilidade técnica dos objetos digitais e 
sua materialidade: o primeiro, a Biblioteca Comum, que promove o incremento do acervo de bibliotecas escolares com objetos digitais sob licenças abertas, e a pesquisa denominada Biblioteca Anônima, a qual analisa um acervo de humanidades elaborado por comunidades discursivas na deep web. Enquanto o primeiro trabalho destaca as potencialidades de concretização da lei 12.244/10, a partir da replicação autorizada, por licenças abertas, dos objetos digitais, de forma local, sem a presença necessária de uma infraestrutura de redes, o segundo evidencia a existência de objetos existentes em redes não públicas, mas que poderiam incrementar o acervo das bibliotecas escolares, caso a lei de direitos autorais fosse flexibilizada. Espera-se que a articulação do arcabouço teórico e as evidências experimentais possam substanciar argumentos para a flexibilização da Lei de Direitos Autorais, no contexto da biblioteca escolar, no sentido de incluir essas questões no cômputo das políticas públicas correlatas ao esforço de concretização da universalização da biblioteca escolar.

Na próxima seção, iniciaremos a síntese de um quadro explicativo para situar a relação de materialidade do objeto digital e seu potencial transformador nas bibliotecas escolares. Em seguida, apresentaremos o projeto Biblioteca Comum e seus resultados preliminares, além de evidenciarmos, na seção seguinte, a formação de acervos clandestinos em redes ocultas na internet. Por fim, após breve sumarização dos experimentos, concluiremos o trabalho, intentando uma modesta contribuição no intenso e prolongado debate.

\section{A ESTRANHEZA DO OBJETO DIGITAL, A “GRANDE FÁBRICA” E A TENSÃO ENTRE OS MODELOS DE GESTÃO DA ESCASSEZ}

A digitalização implica mudanças ontológicas nos objetos. Os objetos digitalizados são constituídos universalmente, ou seja, têm a mesma materialidade, são feitos de um fluxo de bits, que adquirem consistência e forma a partir de um mesmo entorno computacional (FELICE; MOREIRA, 2018). Diferentes objetos são constituídos, no meio digital, materialmente das mesmas coisas: energia, eletricidade, informação. Conceitos esses operados na máquina universal, lembremos, concebida, desde 0 início, para realizar as mesmas operações, diferenciadas apenas em seu conjunto básico de instruções. Se, por um lado, a máquina universal estabelece que a diferença seja constituída pelas mesmas operações, por outro, concebe a diferença de cada objeto como um registro particular da mesma escrita universal, parametrizada diferentemente, mas sob um mesmo código. Se os objetos físicos encontram diferenças em sua substância, seguindo a tradição aristotélica, os objetos digitais lastreiamse, apenas, em diferenças formais, participando todos da mesma estruturalidade computacional. 
A participação em uma mesma estruturalidade, ou seja, da mesma substância e composição formal, implica que sua duplicação rompa uma característica fundamental dos objetos físicos: 0 fato de uma cópia ser sempre diferente do original. A singularidade da origem, nos objetos físicos, não pode ser duplicada, havendo sempre uma diferença irreparável na cópia, mesmo que esta seja muito próxima, alguma singularidade em seu estatuto de "coisa", ou seja, sua forma ímpar e singular de ocupar um lugar no tempo e no espaço (HEIDEGGER; MORUJÃo, 2002). Com o objeto digital, não há essa diferença, pois tanto a cópia quanto o original têm a mesma substância e mecanismo formal. Não há alteridade nem a possibilidade de apontamento da falsidade, senão por outros artifícios, que devem ser adicionados posteriormente, como metadados, certificações digitais, carimbos de tempo, etc. As duplicações aproximam-se, portanto, do conceito de réplica, em que não há perda na troca e a reversibilidade seja completa (FUCCI, 2018).

0 conceito de escassez, que fundamenta a economia (ROBBINS, 1932), está no centro dos circuitos econômicos "tradicionais", por assim dizer, em que o trânsito, a duplicação e a troca dos objetos implicam, ontologicamente, o estabelecimento de pares de opostos - produtor/consumidor, comprador/vendedor, crédito/débito, etc. Se, no objeto digital, não há como copiar, apenas replicar, e nada se perde, então não se produz escassez no processo de duplicação, imprimindo, por fim, uma diferença dos circuitos econômicos físicos. As réplicas digitais seriam "não rivais", ou seja, não produziriam escassez ao serem transitadas, comercializadas ou trocadas. Desse modo, seriam também "não excludentes", no sentido de um usuário não impedir o usufruto do objeto por outro usuário (BAUWENS, 2016). A escassez, empregada para conservar e possibilitar as trocas comerciais "tradicionais", seria implementada a posteriori, sob a forma de direitos autorais, permissões de uso e reprodução, em um processo alienígena ao próprio desenho do objeto digital, que seria, por fim, deslocado para a prestação de serviços, disponibilização e garantia de acesso. 0 barateamento do aparato computacional, por sua vez, completaria o cenário de replicação, deslocando a escassez do registro ontológico dos objetos para a promoção de serviços de manutenção, acesso e preservação (DAVIS, 1995).

A tecnologia, se pensada com Arthur (2009), enquanto um esforço de orquestrar a participação dos objetos em determinado contexto, restringindo suas possibilidades de ação ontológica a apenas uma faixa de atualização de suas propriedades possíveis, herdaria, em sua aparição digital, essas propriedades de replicação e ausência de escassez. Se considerarmos o contexto, com Braman (2004), em que a tecnologia digital se manifesta como uma estrutura material determinante para a presença 
e relação entre os objetos, seus atores e seus entornos e políticas, entenderemos esse "ecossistema" enquanto um regime informacional global, plasmado atualmente pela internet e sua estrutura física - de redes, protocolos de comunicação e aplicações - que unifica os objetos e suas relações em uma "grande fábrica", no sentido sintetizado por Rifkin (2014), de abarcar os modos de socialização, produção e distribuição, em um modelo global de representação e operação.

Nas décadas de 1970 e 1980, no início da indústria de informática, os atores do novo mercado deram início ao negócio de software, que aqui compreenderemos como o próprio conceito de tecnologia comentado por Arthur (2009): um arranjo funcional entre objetos digitais, uma conexão entre sistemas e subsistemas coordenados em um contexto computacional. Sendo digital, esse cômputo de objetos relacionados pode ser infinitamente replicado a um baixo custo. Essa característica tencionou o novo mercado desde seu início, tornando a produção de escassez necessária para a formação de um circuito econômico. A escassez foi, dessa forma inicial, erguida a partir da propriedade intelectual e seu aparato jurídico (PIMENTEL; SILVA, 2014).

Se os direitos autorais foram gradualmente sendo aperfeiçoados a partir do século XVIII, para proteger a autoria de obras do espírito e garantir juridicamente a seção de direitos patrimoniais e viabilizar a nascente indústria cultural (BUAINAIN et al., 2011), na indústria de software, esse expediente foi usado em um cenário ainda mais radical de reprodutibilidade técnica. Essa tensão entre modelos de negócios viáveis pela produção da escassez e as condições radicais de reprodutibilidade técnica da tecnologia digital não tardou em ser explorada enquanto um novo motor na própria indústria de software (MARTINS FILHO, 1998).

Devemos salientar, neste trabalho, que, longe de procurar uma resolução conceitual sobre 0 problema da propriedade intelectual, discutida arduamente por diferentes escolas de pensamento, em prós e contras (KINSELLA, 2010), procuramos entender a relação própria do processo de escassez, como uma condição necessária para o estabelecimento de um modelo de negócio, uma indústria, ou um modo de produção e organização social. Se a condição do estabelecimento da indústria criativa, de acordo com Buainain et al. (2011), é o estabelecimento da propriedade intelectual, e, portanto, do gerenciamento legal da escassez de bens "não rivais" e "não excludentes", outros dispositivos jurídicos de propriedade intelectual se apropriaram das condições dos objetos digitais de mudar esse registro.

0 movimento Software Livre (SL), por intermédio da Free Software Foundation (Fundação para 0 Software Livre -FSF), passou a oferecer, já no início da década de 1990, um dispositivo jurídico (Licença Pública Geral - GNU), que propunha assegurar a liberdade de executar o programa compartilhado, 
ter acesso ao seu código-fonte, para estudá-lo e modificá-lo, compartilhar as cópias aperfeiçoadas e poder executá-las livremente, fortalecendo sua comunidade de usuários. Destacamos que um modelo de negócios, baseado nas possibilidades de reprodutibilidade técnica dos objetos digitais, passava a existir, justamente, deslocando o manejo jurídico da escassez dos objetos para os sujeitos, que agregariam um conjunto de produtos e serviços escassos e, portanto, economicamente viáveis, como suporte técnico, serviços de consultoria e modelos educacionais, os quais restabeleceriam os circuitos econômicos da indústria de software, em outros termos (TORRES, 2013).

0 exemplo paradigmático de sucesso desse modelo foi a criação, implementação e manutenção do sistema operacional Linux, nos anos de 1990, que conta, até hoje, com uma rede crescente de desenvolvedores voluntários, empresas e fundações, os quais se articulam em um "ecossistema" produtivo descentralizado, não hierarquizado e conectivo de desenvolvimento, que, mesmo contrariando os princípios centralizados, hierarquizados e formais da empresa moderna, produz um sistema com a qualidade necessária para oferecer soluções de missão crítica a diversas instituições globais (MOODY, 2002).

1. O sucesso do modelo aberto de articulação de sistemas com comunidades de desenvolvedores, empresas e fundações, em que desenvolvedores, produtores e consumidores se confundem, ganhou notoriedade, diversidade e viabilidade comercial, na década de 1990, fornecendo subsídios para outros empreendimentos, como bancos de dados, navegadores de internet e suítes de escritório, produzindo toda uma cultura de compartilhamento, pensamento hacker e modos de organização. 0 florescimento da cultura de compartilhamento e seus modelos de organização, no entanto, não conciliou os direitos autorais e a convergência digital.

Conforme os objetos digitais ganharam hegemonia no campo da cultura (REINSEL; GANTZ; RYDNING, 2018), passando a assimilar as obras produzidas pelo espírito, como imagens, músicas e filmes, na primeira década dos anos 2000, tornando esses produtos partícipes da mesma "fábrica" e, portanto, súditos do mesmo regime de informação, a tensão com os direitos autorais chegou a um ponto inegociável. Assim, o conflito entre o manejo de diferentes materialidades, diferentes circuitos de produção de escassez e modelos de negócio tornou-se insustentável (SIMON; VIEIRA, 2008). 0 exemplo paradigmático desse conflito foi a série de embates jurídicos entre a indústria fonográfica americana e o sistema de compartilhamento de músicas Napster².

2 Ver MusicDish e-Journal - Story of a Revolution: Napster \& the Music Industry. Disponível em: http://www.musicdish.com/ma$\mathrm{g} / \mathrm{?id}=1941$. Acesso em: 5 fev. 2020. 
Se, na década de 1990, o movimento Software Livre buscou assimilar a materialidade digital à indústria de software, integrando suas propriedades e reprodutibilidade técnica a um dispositivo jurídico - a GPL -, que viabilizou um novo modelo bem-sucedido de organização, produção e sociabilidade, na década seguinte, outra iniciativa procurou integrar essas características à tensa área dos direitos autorais no mundo digital: o Creative Commons (CC).

Inspirado no sucesso do SL, o CC é uma organização sem fins lucrativos ${ }^{3}$, que produziu um conjunto de dispositivos jurídicos capazes de disponibilizar, aos produtores e consumidores de conteúdo digital, permissões preestabelecidas pelos criadores, as quais ficam explicitamente expostas na própria obra. Dessa forma, os consumidores já sabem de antemão quais permissões estão legalmente disponíveis (BRANCO; BRITTO, 2013). As licenças podem variar, conforme a escolha prévia do autor, 0 qual pode adicionar um conjunto combinado de condições, como a permissão de copiar livremente 0 conteúdo, desde que respeitada a autoria, a permissão ou não de alterar a obra ou ainda fazer-Ihe uso comercial ou não, entre outras ${ }^{4}$.

Devemos destacar que, assim como o SL abriu um novo circuito, um novo modelo de socialização e produção, na nascente indústria de software, o CC também afirmou as propriedades de compartilhamento dos objetos digitais, nas décadas seguintes aos anos 2000, enquanto os produtores de conteúdo ganharam um instrumento de segurança jurídica, viabilizando um abundante conjunto de iniciativas, como a enciclopédia colaborativa Wikipédia ${ }^{5}$ o movimento pela ciência aberta ${ }^{6}$, o movimento pelos princípios abertos para herança cultural - OpenGLANP - e os Recursos Educacionais Abertos (REA), que destacaremos.

Os REA são materiais de ensino, aprendizagem e investigação em quaisquer suportes, digitais ou outros, que se situem no domínio público ou tenham sido divulgados sob licença aberta, permitindo acesso, uso, adaptação e redistribuição, gratuitos, por terceiros, mediante a nenhuma ou poucas restrições (HENRIQUES, 2017).

No início da década de 2000, o movimento REA surgiu como um conjunto de intenções, aproximando o poder de replicação dos objetos digitais à disseminação da web (AMIEL; GONSALES; SEBRIAM, 2018). 0 sucesso do SL inspirou a ampliação das possibilidades de difusão do conhecimento e da cultura, e não somente os programas de computadores, associando as propriedades de replicação

3 Detalhes em: https://creativecommons.org.

4 Verifique todos os tipos de licença CC em: https://creativecommons.org/use-remix/cc-licenses.

5 Veja: https://pt.wikipedia.org/wiki/Wikip\%C3\%A9dia:P\%C3\%A1gina_principal.

6 Veja mais sobre movimento Open Science e CC aqui: https://creativecommons.org/about/program-areas/open-science/.

7 Veja detalhes sobre o movimento pelo acesso aberto à herança cultural em: https://openglam.org. 
digital a um dispositivo jurídico apropriado, as licenças abertas, como o CC. Após duas décadas, também os REA possibilitaram um conjunto de novas estratégias, nichos de produção e consumo e modelos de negócios especializados, vide a priorização governamental de seu uso ${ }^{8}$.

Os objetos digitais, dessa forma, unificados pelo mesmo regime de informação, associados a dispositivos jurídicos abertos, seguem suas características de reprodutibilidade técnica infinita, pela capilaridade da malha de conexões de dados da internet, populando de serviços gratuitos, abertos e acessíveis à vida de seus usuários (ANDERSON, 2009). 0 custo de produção e distribuição de produtos e serviços tem caído vertiginosamente, conforme os modelos de negócios na internet se consolidam. 0 modelo Freemium, por exemplo, em que os usuários têm acesso a um conjunto limitado, mas gratuito, de serviços, pagando por versões mais sofisticadas, tem se tornado hegemônico, nas últimas décadas, apesar de os críticos apontarem o uso da informação dos usuários, tanto de forma legal quanto ilegal, como principal fonte de receita desses serviços, gerando um amplo campo de eclosão de escândalos corporativos (ZUBOFF, 2018).

A "grande fábrica" digital contemporânea tende, portanto, a uma escala de abundância sem precedentes, ao unificar, sob um mesmo regime de informação, os processos de concepção intelectual, produção e distribuição de objetos. Existem, no entanto, entraves para a participação nos processos produtivos da "grande fábrica". Há um tipo de letramento necessário, condições de participação nas cadeias produtivas, formas explícitas de exclusão, que podem ser resumidas, no âmbito deste trabalho, à não participação do pensamento computacional, que, conforme sintetizado por Tedre e Denning (2016), seria a capacidade de raciocinar e operar algoritmicamente, abstraindo problemas do mundo do trabalho e da vida cotidiana, em modelos computacionais solucionáveis e passíveis de operação dentro do regime de informação da "grande fábrica" contemporânea.

Assim, a participação na "grande fábrica" contemporânea ganharia contornos contraditórios, no sentido de, por um lado, oferecer um contexto de produção unificado e cada vez mais acessível e aberto, materialmente falando, ubíquo, e, por outro, exigir capacidades e letramentos especializados, destacando o pensamento computacional, o qual necessita de profissionais capazes de trabalhar em equipes interdisciplinares orientados à resolução cotidiana de problemas abordados computacionalmente. 0 pensamento computacional, dessa maneira, emergiria como a língua franca, necessária à participação das cadeias produtivas da "grande fábrica" global, um conjunto essencial de habilidades universais a serem adquiridas pelos estudantes (MORENO-LEÓN et al., 2018).

$8 \quad$ Veja mais detalhes em: https://plataformaintegrada.mec.gov.br. 
Pensar a biblioteca escolar como integrante da "grande fábrica" contemporânea tornaria essas contradições ainda mais visíveis. Um dos desafios das bibliotecas contemporâneas é, segundo Jesus e Cunha (2019), encontrar o uso apropriado das novas tecnologias e modos de produção, servindo às necessidades de sua nova geração de usuários. Assim, uma gama de questões se impõe aos bibliotecários atuaslmente, desde como integrar recursos até as possibilidades de usar acervos digitais, realidade aumentada, impressoras 3D, redes sociais, jogos, entre outros, no intuito de tornar as bibliotecas espaços relevantes.

Essa busca por relevância, no entanto, fica condicionada a uma equipe de profissionais especializados, computacionalmente letrados, bem como ao acesso à infraestrutura de redes, sistemas de gestão de acervos, suporte técnico, manutenção de direitos autorais, acesso a periódicos e outros serviços, tornando a biblioteca um espaço cada vez mais caro de ser implementado e mantido, com alto custo total de propriedade (Total Cost of Ownership -TCO) que Longo e Sakata (2018) sintetizam como sendo a expectativa financeira de investimento e manutenção dos custos totais, implícitos e explícitos, de um investimento.

As instituições de memória - bibliotecas, arquivos e museus -, como sintetiza Almeida (2016), por possuírem procedimentos semelhantes de armazenamento, preservação, organização e segurança de objetos digitais, passariam a ampliar sua dependência do trabalho integrado de um conjunto diverso de profissionais, além de depender de uma infraestrutura comum de TIC - bancos de dados, servidores de web, redes e segurança cibernética, etc.

Essa dependência de infraestrutura e pessoal especializado ampliaria o custo total de propriedade interno das organizações e justificaria, então, o uso de nuvens corporativas, que diminuiriam, idealmente, esses custos. Uma nuvem, em síntese, é um conjunto articulado de produtos e serviços que substituem os processos realizados internamente nas organizações (MAKHLOUF, 2020). Essa nuvem é disponibilizada, normalmente, por um grande ator no mercado de tecnologia, mediante a um contrato, que promete poupar o cliente das despesas de manter uma infraestrutura interna e recursos humanos.

Se, por um lado, a nuvem pouparia as organizações o custo de investirem e manterem a infraestrutura necessária à operação de seus processos digitais, por outro, segundo Amoore (2018), ampliaria a dependência de uma conexão de qualidade à internet, fragilizaria a segurança de missões críticas e diminuiria a soberania das organizações, no sentido de torná-las vulneráveis a sua interrupção, ou submetendo os dados organizacionais a diferentes jurisdições, implicando insegurança jurídica. 
As soluções em nuvem, desta maneira, tenderiam a centralizar o conjunto de produtos e serviços prestados, monopolizando o setor de informação ao reduzir drasticamente o custo total de propriedade das instituições. Essa redução de custos, no entanto, implicaria diminuição da soberania de dados e permanente adesão à tecnologia (DE FILIPPI; MCCARTHY, 2012).

Em resumo, escutando os alertas dos autores supracitados, concluímos que um desafio espreita as bibliotecas e instituições de memória em geral: como ampliar seu leque de serviços, acervo e produtos informacionais, para acompanhar as demandas da sociedade contemporânea, sem encarecer seu custo total de propriedade ou perder a soberania de seus objetos e processos? De outra forma: como, mesmo em um mar de abundância, patrocinado pelos REA, os objetos digitais e a nuvem, poderiam as bibliotecas não padecer de um custo crescente de implementação e manutenção, ou ceder a mecanismos centrais de controle, que poderiam empalidecer seu caráter local e comunitário?

Se, de um modo, como explicamos nesta seção, os objetos digitais, conjugados na "grande fábrica", são infinitamente replicáveis, de outro, são adaptados a circuitos econômicos tradicionais, pela instalação de uma escassez deslocada, dada pelos direitos autorais, serviços de TIC e infraestrutura. Em poucas palavras, a nuvem concentra poder. Assim, uma grande e única biblioteca escolar na nuvem, nacional, ubíqua e virtual, traria os benefícios de um serviço universalizado, mas também as implicações políticas de um poder centralizado, deslocado das necessidades particulares e das demandas singulares de sua comunidade. Este é um cenário que deve ser incansavelmente questionado por aqueles que testemunharam as promessas iniciais e apolíneas, de autonomia e liberdade, da cibercultura dos idos da década de 1990, para o jogo da vigilância corporativa dos dias atuais.

Na próxima seção, apresentaremos o projeto Biblioteca Comum, que procura evidenciar as possibilidades de implementação da Lei 12.244/10, aplicando as propriedades dos objetos digitais no sentido de baratear o custo total de propriedade de bibliotecas, mantendo seu caráter local, conjugando o Software Livre e os REA.

\section{PROJETO BIBLIOTECA COMUM}

0 projeto de extensão Biblioteca Comum $(\mathrm{BC})$ é realizado na Universidade Estadual de Londrina (UEL), desde 2013, e tem como objetivo incrementar 0 acervo digital das bibliotecas escolares em busca da universalização de seu acesso, em consonância com os esforços promulgados pela Lei № 
12.244, de 24 de maio de 2010, e a Lei Castilho, n. ${ }^{\circ}$ 13.696, de 12 de julho de 2018, que propõem um marco legal para a promoção do livro, da leitura e da biblioteca no Brasil ${ }^{9}$.

Para isso, buscamos Recursos Educacionais Abertos (obras em domínio público ou sob a licença Creative Commons) e os integramos a um sistema aberto de gestão de bibliotecas. 0 resultado é instalado em qualquer computador disponível na escola. Atualmente conta com mais de 3.000 livros clássicos e científicos, 500 vídeos didáticos, 700 áudios e 15.000 ilustrações, documentos selecionados e destinados à educação continuada dos professores e ao auxílio na preparação de suas aulas. Além disso, a ideia é que este volume de informação possa ser gravado em um pen drive popular de 32 GB.

As obras ficam em um computador local, assim não é preciso ter acesso à internet para usar a biblioteca, que pode ser acessada inclusive pelos celulares e tablets dos alunos, por meio de sua rede interna sem fio.

\subsection{Desenvolvimento}

A implementação da Biblioteca Comum segue uma metodologia de prototipação, em ciclos de desenvolvimento circulares e curtos - típicos das metodologias ágeis (EDER, 2015) - seguidos da disponibilização de versões, conforme a maturidade do projeto. 0 projeto é organizado como um living lab, conforme sintetiza Silva (2012), que propõe uma forte interação local para a inovação, baseada na prototipação e experimentação. A maturidade do projeto é estabelecida pelo avanço e revisão contínua de quatro processos distintos, mas correlacionados:

1) Coleta - Objetos digitais de livre circulação são "baixados" para o diretório do projeto. Estes devem estar sob domínio público ou sob a licença Creative Commons, para evitar problemas judiciais com suas cópias. Estes objetos são disponibilizados por iniciativas diversas, como 0 site domínio público (http://www.dominiopublico.gov.br), livros SciELO (http://books.scielo. org), editoras privadas, repositórios institucionais, entre outras.

2) Extração - 0 conjunto de dados produzidos na coleta de títulos será minerado, periódica e programaticamente, para que os metadados de seus registros sejam extraídos, via análise lexical, ontologias e anotações semânticas, identificando e indexando suas entidades significativas.

9 A descrição da Biblioteca Comum, presente nesta seção, foi adaptada do site do projeto, disponível em: http://bc.precog.com.br. Devido à volatilidade das edições no site, é possível que exista diferença no conteúdo. Recomendamos que o leitor recorra ao site para obter as informações mais atualizadas. 
3) Catalogação - 0 resultado desse processo massivo e automatizado é refinado colaborativamente por profissionais da informação, para incremento de sua qualidade e posterior integração aos sistemas de gestão de bibliotecas, por meio da produção de um catálogo, ampliando a encontrabilidade dos objetos coletados.

4) Disseminação - A tecnologia desenvolvida é integrada às práticas pedagógicas, sugeridas pela curricularização da extensão universitária, disseminando os resultados do projeto, beneficiando professores, escolas e alunos, proporcionando aos estudantes uma experiência prática de aplicação.

\section{RESULTADOS PARCIAIS}

Cada processo implica resultados específicos, que indicam a maturidade do projeto como um todo. Na fase inicial de coleta, foram minerados mais de 190.000 objetos digitais abertos em 4,4 TB de dados, contendo aproximadamente: 54.000 textos (117 GB), 33.600 vídeos (4,7 TB), 3.500 áudios (24 GB) e 98.600 imagens (102 GB), depositados no diretório do projeto ${ }^{10}$.

Como resultado do segundo processo (extração), produzimos os buscadores, que são sistemas de recuperação de arquivos selecionados, conjugando um critério de relevância e a ocupação de espaço no dispositivo, buscando ofertar o maior número de arquivos importantes em um menor espaço possível. Estes sistemas foram pensados para que se possa difundir, copiar e utilizar, sem que seja necessária a instalação de nenhum programa de computador, além do navegador, tornando praticamente nulo seu custo total de propriedade. São eles:

Bc-texto ${ }^{11}$ - Dos textos baixados durante a fase de coleta, selecionamos 3.000 livros digitalizados, clássicos e científicos, para formar um acervo inicial, atentando para que caibam em pen drives de 8 GB.

Bc-clipart ${ }^{12}$ - 0 buscador de cliparts disponibiliza quase 15.000 desenhos para ilustração de trabalhos escolares, apresentações e publicações, diretamente em um pen drive, a fim de agilizar as tarefas de professores e alunos.

10 Acesse em: https://bit.ly/3anFd2h.

11 Veja uma demonstração do Bc-texto em: http://www.precog.com.br/bc-texto.

12 Veja uma demonstração do Bc-clipart em: http://www.precog.com.br/bc-clipart. 
Bc-vidmin ${ }^{13}$ - 0 buscador de vídeos da Biblioteca Comum reúne mais de 500 vídeos educacionais, ocupando um espaço de menos de $8 \mathrm{~GB}$, podendo ser copiados em pen drives de baixo custo. Bc-cordel ${ }^{14}$ - Considerada como patrimônio cultural do Brasil, a literatura de cordel auxilia na formação de professores. 0 buscador de literatura de cordel reúne e classifica folhetos, disponibilizados em domínio público.

Bc-audio ${ }^{15}$ - 0 buscador de áudios da Biblioteca Comum é uma compilação de 700 arquivos de áudio categorizados, que cabem em um pen drive de 8 GB.

Kit Escola ${ }^{16}$ - Ainda em fase experimental de catalogação, integra os arquivos dos buscadores ao Biblivre ${ }^{17}$, gerenciador de bibliotecas de código aberto, por meio de registros MARC II, importados à base de dados do sistema, após sua instalação. Na versão atual, contamos com todo acervo dos buscadores, que cabem em um pen drive popular de $32 \mathrm{~GB}$. Iniciaremos, assim, os primeiros testes de instalação da Biblioteca Comum em escolas, em sua versão institucional, utilizando o Biblivre e sua arquitetura web, para criar serviços internos que possam distribuir 0 conteúdo ofertado, por meio de buscas avançadas.

\subsection{Disseminação}

Para disseminação, teste dos resultados e prática de laboratório, integramos a cópia, aplicação e avaliação dos buscadores ao método de ensino e avaliação da disciplina "Plataformas Digitais Aplicadas à Ciência da Informaç̧ão", no 2CIN145, do Departamento de Ciência da Informação da UEL, em que os alunos foram incentivados a instalar os buscadores em computadores pessoais de professores da rede pública, aplicando em campo os conhecimentos obtidos. Além de conjugar uma vivência prática aos benefícios da tecnologia desenvolvida, aplicamos uma metodologia ativa, que chamamos de "laboratório invertido", em que aproveitamos o poder computacional pessoal dos alunos como instrumento pedagógico (FRANKLIN, 2017).

A integração entre um projeto de extensão e uma disciplina de graduação da UEL segue as orientações para curricularização da extensão universitária, que deverá ser um desafio à universidade

\footnotetext{
13 Veja uma demonstração do Bc-vidmin em: http://www.precog.com.br/bc-vidmin.

14 Veja uma demonstração do Bc-cordel em: http://www.precog.com.br/bc-cordel.

15 Veja uma demonstração do Bc-audio em: http://precog.com.br/bc-audio.

16 Segue um exemplo de implementação do Kit Escola: http://bc.precog.com.br.

17 Veja o site do projeto em: http://biblivre.org.br.
} 
brasileira nos próximos anos (IMPERATORE; PEDDE; IMPERATORE, 2015). 0 mapa obtido das mais de 220 instalações dos buscadores, no entorno da UEL, segue abaixo, na Figura $1^{18}$ :

Figura 1 - Mapa de instalações do projeto Biblioteca Comum

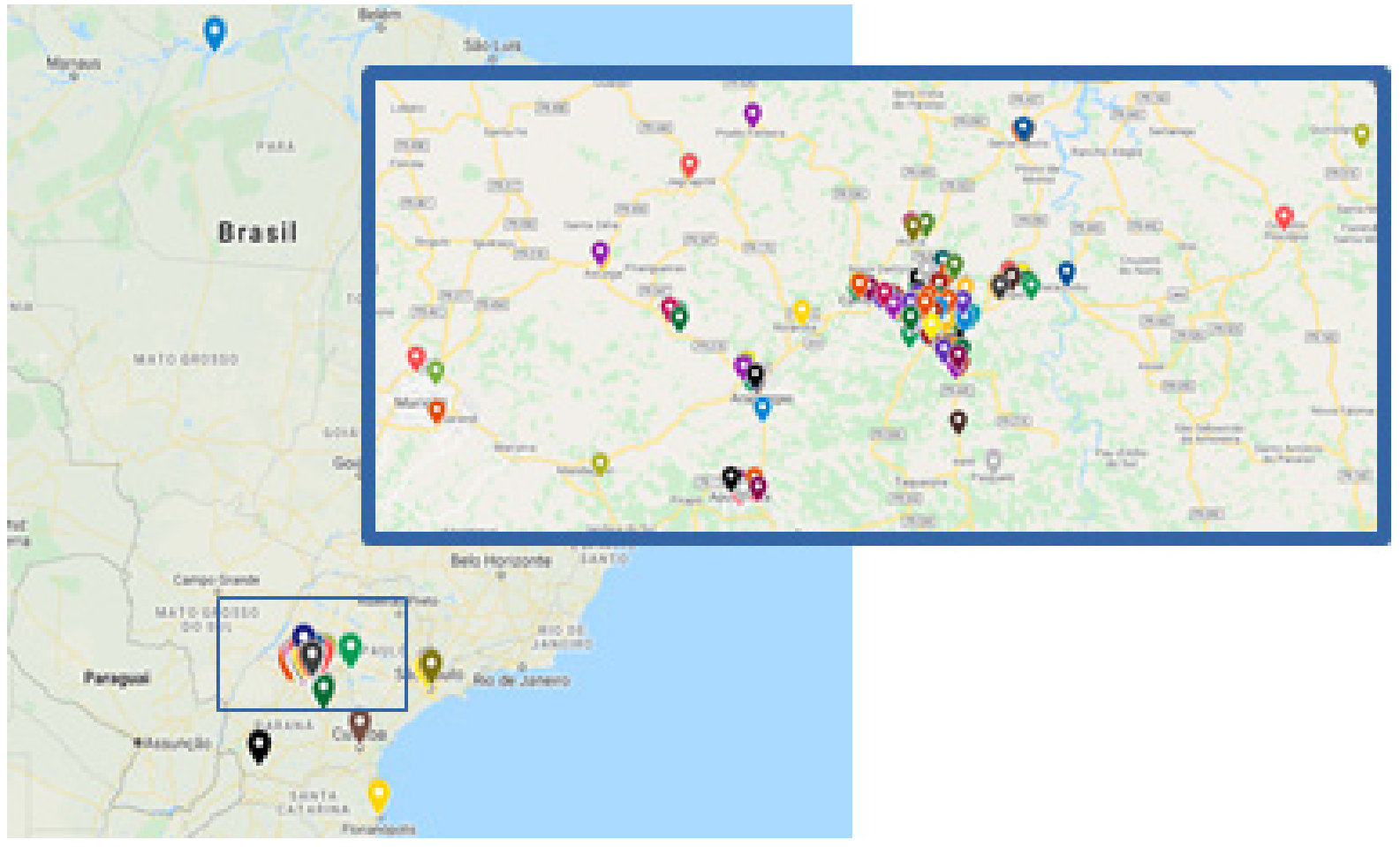

Fonte: Autor.

\subsection{A Biblioteca Anônima}

Os resultados parciais do projeto Biblioteca Comum sugerem o grande potencial da utilização dos Recursos Educacionais Abertos, associados ao uso de Software Livre, na implementação da Lei 12.244/10, inclusive em áreas de acesso precário ou inexistente à internet, promovendo uma solução local, independente de nuvens corporativas. Esses resultados, no entanto, são condicionados ao uso de licenças abertas, previamente atribuídas por editores e autores, que tornam a circulação desses recursos perfeitamente legal.

Outras iniciativas, no entanto, devem ainda ser destacadas como um vetor potencial de implementação da Lei 12.244/10. Sabemos que, desde 0 início da década de 2000, com 0 aumento gradual do uso de banda larga no Brasil, a eclosão das redes sociais, a partir de 2012, e 0 aumento da

180 mapa de instalações está disponível em: https://bit.ly/2QFudFR. 
velocidade da internet nas áreas metropolitanas, grupos descentralizados passaram a digitalizar livros e distribuí-Ios na deep web (FRANKLIN, 2019). Esses livros não estão sob uma licença aberta e, portanto, não têm sua reprodução autorizada pela lei de direitos autorais.

Em síntese, a deep web é um termo genérico que designa toda internet que não está disponível publicamente, não participando, dessa forma, nem dos mecanismos de busca, nem do conjunto de serviços de acesso geral aos usuários da internet. Participam da deep web páginas de uso restrito, bancos de dados particulares, grupos protegidos em redes sociais, etc. Dentro do conceito da deep web, existe a dark web, que são redes obscurecidas por sistemas de criptografia e roteamento alternativo, tornando anônimos seus usuários, sua localização e o conteúdo trafegado (GEHL, 2018). A rede Tor ${ }^{19}$ é o exemplo paradigmático de dark web, apesar de existir um número crescente de outros exemplos. A darknet, outra arquitetura de rede na deep web, descentraliza, por sua vez, o armazenamento dos arquivos, utilizando a tecnologia ponto a ponto. Seu exemplo paradigmático é o Bittorrent ${ }^{20}$, responsável pela difusão da pirataria crescente de filmes e outros arquivos de mídia, em que os arquivos ficam espalhados em computadores pessoais e não em um servidor central, dificultando as ações de controle policial (W00D, 2011).

A existência material de um acervo alternativo, cada vez mais robusto, que aqui destacamos um caso especializado nas humanidades, que chamaremos de Biblioteca Anônima, cujo acervo chega próximo a duas dezenas de milhares de livros, em 190 GB de dados, como mostrado no Gráfico 1, indica a atualização da biblioteca como uma prática da sociedade, independente dos dispositivos legais que tentam regular o circuito legítimo de seu estabelecimento (FRANKLIN, 2019). Se as bibliotecas comunitárias já carregam uma desconfiança dos poderes estatais, como forma de controlar e cobrar financeiramente sua existência e, por isso, costumam manter-se incógnitas e invisíveis (FERNANDEZ et al., 2018), as bibliotecas digitais clandestinas na deep web são possíveis apenas pela proliferação das redes obscurecidas, que não oferecem circulação pública, permanecendo inacessíveis ao grande público e ao controle oficial. A própria existência material das bibliotecas digitais clandestinas indica uma tensão entre as práticas sociais contemporâneas, a vitalidade da biblioteca e a lei de direitos autorais, que oferece um contorno institucional obsoleto para sua existência.

19 Ver o site do projeto Tor em: https://www.torproject.org.

20 Ver site do projeto em: https://www.bittorrent.com. 
Gráfico 1 - Evolução da quantidade de livros no acervo da Biblioteca Anônima

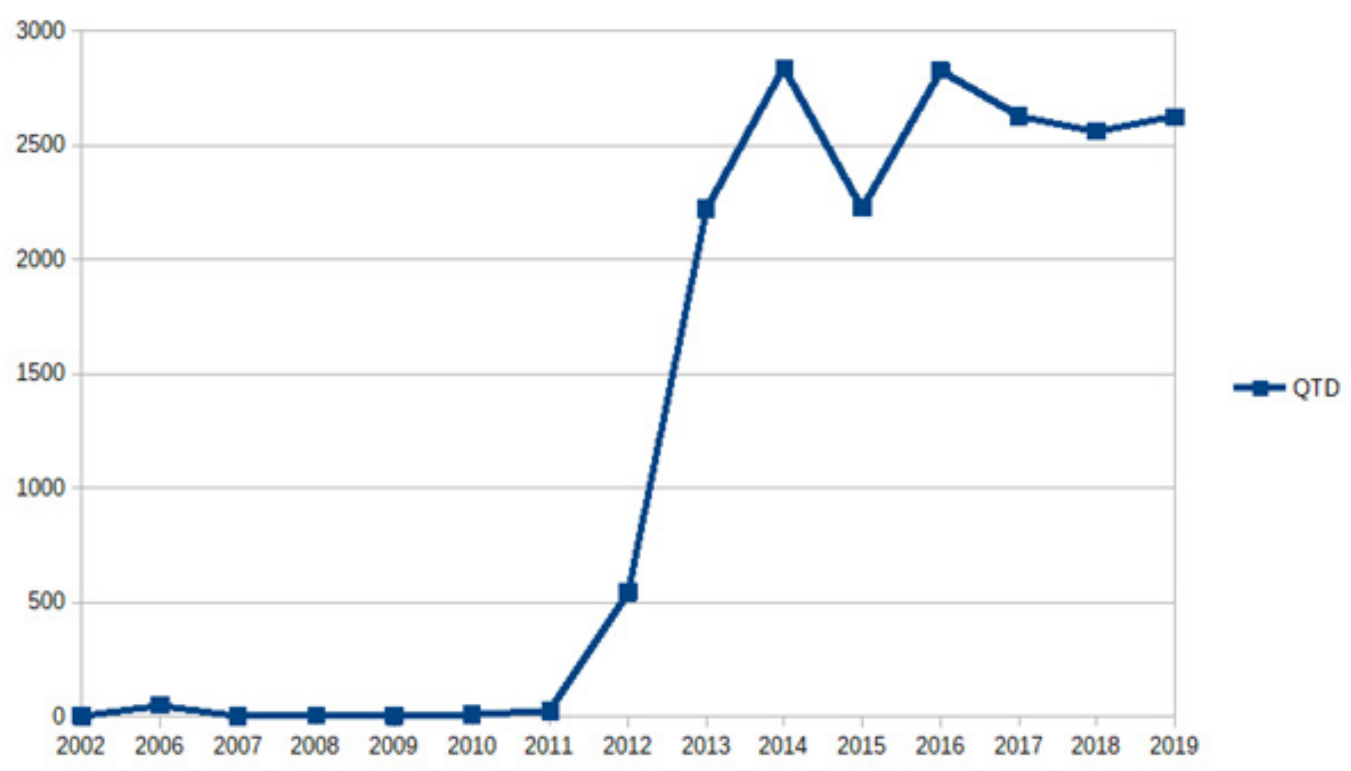

Fonte: Adaptado de Franklin (2019).

A Lei de Direitos Autorais (LDA), nº 9.610, foi instaurada em 1998, no Brasil (FUNDAÇÃO GETÚLIO VARGAS, 2011). Ela fornece o conjunto de dispositivos jurídicos que sustentam a indústria criativa, a partir dos conceitos de propriedade intelectual (BUAINAIN et al., 2011). Esse conjunto de dispositivos, no entanto, é anterior à eclosão da internet, da hegemonia do objeto digital e sua reprodutibilidade técnica, do advento do Creative Commons e da consolidação dos REA, como estratégia de difusão da cultura.

Durante as últimas décadas, podemos destacar duas consultas públicas com iniciativas de alteração da LDA, para compatibilização com as práticas digitais atuais, no sentido de flexibilizar os dispositivos da propriedade intelectual, a fim de permitir a cópia de objetos em um contexto controlado. A primeira ocorreu em 2010, apontando as seguintes sugestões:

Para os cidadãos, as propostas de revisão na lei de direito de autor pode trazer algumas mudanças, tais como para:

a) 0 acesso à cultura e ao conhecimento: havendo novas permissões para uso de obras sem necessidade de pagamento ou prévia autorização, tais como os usos para finalidade didática, adaptação e reprodução sem finalidade comercial;

b) a reprodução de obra esgotada: permitida, no entanto sem finalidade comercial, a reprodução de obras desde que a última publicação esteja esgotada;

c) a reprografia de livros: licenciamento das obras com a garantia de pagamento de uma retribuição a autores e editores que permitirem a reprodução de seus livros por serviços reprográficos comerciais;

d) 0 uso privado de cópias: a utilização da obra, via cópia reprográfica, para uso individual e não comercial das obras pode ser autorizada em alguns casos, tais como para cópia de segurança e para fins de portabilidade e interoperabilidade de arquivos digitais. (BUAINAIN et al., 2011 p. 25). 
Em 2019, outra consulta pública ocorreu no sentido de coletar direcionamentos para uma possível alteração na LDA21. Essas duas iniciativas, que ainda não se concretizaram como mudança efetiva na lei, demonstram a complexidade da questão e a dificuldade em propiciar equilíbrio, entre a necessidade de acesso do cidadão ao bem cultural e à indústria criativa.

Não obstante essa tensão e dificuldade, a existência material de um acervo clandestino, que circula nas redes obscurecidas, para além dos controles oficiais do Estado, apenas indica a urgência de compatibilizar as necessidades das bibliotecas escolares, sua atualização espontânea e a lei que versa sobre sua universalização.

\section{DIFICULDADES MATERIAIS SUPERÁVEIS}

Os resultados parciais do projeto Biblioteca Comum sugerem que é possível incrementar o acervo das bibliotecas escolares, de forma legal, mesmo daquelas com acesso precário ou inexistente à internet, usando Recursos Educacionais Abertos, sem aumentar o custo total de propriedade das instituições. Por outro lado, os achados dos estudos da Biblioteca Anônima apontam a existência de uma quantidade nada desprezível de livros digitalizados, que não podem circular na web pública devido à LDA, mas que se fazem presentes, à sua revelia, nas redes obscurecidas.

Ambos trabalhos mostram as propriedades de replicação material dos objetos digitais. Se a Biblioteca Comum evidencia uma difusão localizada, independente da conectividade das escolas à internet, de pessoa a pessoa, a Biblioteca Anônima se atualiza nas áreas de grande conectividade, com usuários capazes de prover a instalação e utilização de sistemas compatíveis com a deep web, 0 que demanda recursos computacionais adicionais ${ }^{22}$. As proporções continentais do Brasil e sua desigualdade social adicionam um desafio à implementação de um quadro de plena conectividade territorial à internet brasileira, sendo que as áreas metropolitanas atingem 70\% dos lares conectados e as rurais 44\% (CETIC, 2019). Enquanto a conectividade é desigual e se dissemina lentamente pelo território, demandando um amplo apoio logístico e implementação de infraestrutura compatível, normalmente implicando custos elevados, a capacidade computacional, no entanto, persiste seu movimento de miniaturização, atualização e barateamento constantes. 0 preço de armazenamento em

21 Para mais informações consulte: Ministério da Cidadania abre consulta pública sobre reforma da Lei de Direitos Autorais - Secretaria Especial da Cultura. Disponível em: http://cultura.gov.br/ministerio-da-cidadania-abre-consulta-publica-sobre-reforma-da-lei-de-direitos-autorais/. Acesso em: 24 mar. 2020.

22 Detalhes em: Tails - Why is Tor slow? Disponível em: <https://tails.boum.org/doc/anonymous_internet/why_tor_is_slow/index. en.html>. Acesso em: 21 maio 2020. 
memória flash, em dispositivos portáteis, os populares pen drives, caiu vertiginosamente, enquanto sua capacidade de armazenamento aumentou exponencialmente (COUGHLIN, 2019). Dessa forma, atualmente, o cidadão comum tem acesso a uma capacidade pessoal de armazenamento de informações digitais inimaginavelmente superior à ocorrida há duas décadas.

Essa capacidade crescente de armazenamento pessoal excede a capilaridade da internet brasileira e sua capacidade de entregar conteúdos digitais, em altas velocidades, oferecendo possibilidades de incremento dos acervos das bibliotecas, como propõem os resultados da Biblioteca Comum. Assim, a materialidade do objeto digital e sua reprodutibilidade técnica tendem a ser hegemônicas, mesmo em ambientes conectados apenas pelos celulares, como áreas rurais e comunidades carentes, em que mais de $97 \%$ das pessoas se conectam à internet apenas por dispositivos móveis, os quais oferecem baixas taxas de transferência de dados (IBGE, 2020).

Sendo possível o translado de objetos digitais por meio de dispositivos portáteis de memória, mesmo em regiões desconectadas, como evidencia a Biblioteca Comum, a participação em redes ocultas, capazes de transladar os dados do acervo da Biblioteca Anônima, é improvável, atualmente, fora das áreas urbanas altamente conectadas no Brasil. Essa situação paradoxal de abundância e escassez só poderia ser minorada se o acervo da Biblioteca Anônima pudesse ser transladado pelos mecanismos pessoais, desconectados, da Biblioteca Comum, possível apenas com a flexibilização da Lei de Direitos Autorais, uma vez que a distribuição de pessoa a pessoa, na escola pública, não ocorreria de forma anônima, sendo oficializada em uma biblioteca escolar.

Em suma, podemos inferir que, se por um lado, a interiorização da internet em alta velocidade para todas as escolas é um desafio no Brasil, aparentemente inexequível nos próximos anos, a hegemonia da materialidade digital e 0 aumento exponencial da capacidade dos dispositivos portáteis de memória parecem habilitar a reprodução de objetos digitais em benefício da implementação da lei 12.244/10. Dada a oficialidade dos acervos das bibliotecas escolares, no entanto, o imenso potencial dos acervos circulantes na deep web não poderia ser aplicado nas bibliotecas escolares sem a flexibilização da LDA. De outra forma, a distribuição de objetos digitais destinados à implementação de acervos nas bibliotecas escolares pode superar as dificuldades de interiorização da internet em banda larga, a partir de Recursos Educacionais Abertos distribuídos pessoa a pessoa, por meio de dispositivos pessoais de memória. Assim, a flexibilização da LDA expandiria essa possibilidade, incluindo os acervos escondidos na deep web, por vias informais, sem a criminalização dos agentes interessados na universalização da biblioteca escolar, pela replicação de objetos digitais. 
0 ponto a ser destacado é que esse conjunto de operações está na ordem do possível, mesmo que as questões correlatas precisem ser melhor compreendidas, em seus aspectos técnicos, jurídicos, éticos e morais, discussões que devem ser agendadas e tratadas futuramente.

\section{CONCLUSÃO}

Neste trabalho, procuramos evidenciar a potencialidade da materialidade dos objetos digitais na universalização das bibliotecas escolares, como demandado pela Lei 12.244/10. Nessa direção, após a síntese do conceito de "grande fábrica", contrastamos qualitativamente os resultados experimentais parciais de dois estudos: a Biblioteca Comum e a Biblioteca Anônima. Concluímos que os objetos digitais podem contribuir para o incremento do acervo das bibliotecas escolares, mesmo com as dificuldades de interiorização da internet no Brasil, pela transmissão dos acervos via dispositivos pessoais de memória, que tem seu preço minorado seguidamente, além do aumento expressivo de sua capacidade de armazenamento e miniaturização material, nos últimos anos. Essa capacidade de difusão, no entanto, não se aplica a objetos digitais de reprodução restrita devido à Lei de Direitos Autorais, impedindo que acervos, organizados e armazenados na deep web, alcancem as escolas, de forma oficial, em suas bibliotecas.

Se os resultados da Biblioteca Comum mostram a potencialidade de difusão de objetos digitais, sob licenças abertas e transmissão local, mesmo em escolas sem a conectividade da internet, os resultados da Biblioteca Anônima apontam que mais objetos digitais poderiam chegar às escolas de áreas rurais e carentes, em caso de flexibilização da Lei de Direitos Autorais. Essa conclusão propõe, portanto, adicionar uma voz ao coro que pede por uma flexibilização na LDA, há quase duas décadas em discussão, no sentido de permitir a reprodução de objetos digitais, no contexto das bibliotecas escolares, como política pública, em seu esforço por universalização.

Apesar da enormidade e complexidade dos temas implicados nesse trabalho, que nos excedem, tanto em capacidade de síntese quanto em habilidade nas disciplinas correlatas, esperamos ter colaborado, dentro das limitações de escopo, evidenciando, experimentalmente, a enorme potencialidade da materialidade digital na implementação da lei 12.244/10.

\section{REFERÊNCIAS}

ALMEIDA, M. C. B. de. Bibliotecas, arquivos e museus: convergências. Revista Conhecimento em Ação, Rio de Janeiro, v. 1, n. 1, jan./jun., 2016. Disponível em: https://revistas.ufrj.br/index.php/rca/ article/view/2737. Acesso em: 14 fev. 2020. 
AMIEL, T.; GONSALES, P.; SEBRIAM, D. Recursos Educacionais Abertos no Brasil: 10 anos de ativismo. EmRede - Revista de Educação a Distância, Porto Alegre, v. 5, n. 2, p. 246-258, 2018. Disponível em: https://www.aunirede.org.br/revista/index.php/emrede/article/view/346. Acesso em: 05 mar. 2020.

AM00RE, L. Cloud geographies: Computing, data, sovereignty. Progress in Human Geography, v. 42 , n. 1, p. 4-24, 2018. Disponível em: https://journals.sagepub.com/doi/10.1177/0309132516662147. Acesso em: 18 mar. 2020.

ANDERSON, C. Free: grátis: o futuro dos preços. Rio de Janeiro: Campus, 2009.

ARTHUR, W. B. The nature of technology: what it is and how it evolves. London: Allen Lane, 2009.

BAUWENS, M. Towards a commons transition policy: re-aligning economics and politics for a commons-centric society. P2P e Inovação, Rio de Janeiro, v. 2, n. 2, p. 62-77, apr. 2016. Disponível em: http://revista.ibict.br/p2p/article/view/1784. Acesso em: 18 mar. 2020.

BRAMAN, S. The Emergent Global Information Policy Regime. In: BRAMAN, S. (org.). The Emergent Global Information Policy Regime. London: Palgrave Macmillan UK, 2004, p. 12-38. (International Political Economy Series). Disponível em: https://doi.org/10.1057/9780230377684_2. Acesso em: 18 mar. 2020.

BRANCO, S.; BRITTO, W. 0 que é Creative Commons? novos modelos de direito autoral em um mundo mais criativo. Rio de Janeiro: Editora FGV, 2013. Disponível em: http://bibliotecadigital.fgv.br/ dspace/handle/10438/11461. Acesso em: 18 mar. 2020.

BRASIL. Câmara dos Deputados. Projeto de Lei 9484 de 2018. Disponível em: https://bit. ly/20TI88W. Acesso em: 10 nov. 2019.

BRASIL. Lei n. ${ }^{0}$ 12.244: Dispõe sobre a universalização das bibliotecas nas instituições de ensino do País. Brasília: Congresso Nacional, 2010.

BUAINAIN, A. M.; MENDES, C. I. C.; SILVA, A. B. de 0. e; CARVALHO, S. M. P. de. Indústria criativa: direitos de autor e acesso à cultura. Liinc em Revista, v. 7, n. 2, 2011. Disponível em: http://revista. ibict.br/liinc/article/view/3319. Acesso em: 18 mar. 2020.

CETIC. Pesquisa sobre o uso das tecnologias de informação e comunicação nos domicílios brasileiros: TIC domicílios, 2019. Disponível em: https://cetic.br/pesquisa/domicilios. Acesso em: 20 maio 2020.

COUGHLIN, Tom. Digital Storage Projections For 2020, Part 2. Forbes. Disponível em: <https:// www.forbes.com/sites/tomcoughlin/2019/12/23/digital-storage-projections-for-2020-part-2/>. Acesso em: 21 maio 2020.

DAVIS, D. The Work of Art in the Age of Digital Reproduction (An Evolving Thesis: 1991-1995). Leonardo, v. 28, n. 5, p. 381-386, 1995. 
DE FILIPPI, P.; MCCARTHY, S. Cloud Computing: Centralization and Data Sovereignty.

Rochester, NY: Social Science Research Network, 2012. Disponível em: https://papers.ssrn.com/ abstract=2167372. Acesso em: 14 fev. 2020.

EDER, S. et al . Diferenciando as abordagens tradicional e ágil de gerenciamento de projetos. Prod., São Paulo, v. 25, n. 3, p. 482-497, Sept. 2015. Disponível em http://www.scielo.br/scielo. php?script=sci_arttext\&pid=S0103-65132015000300482\&Ing=en\&nrm=iso. Acesso em 13 out. 2016. Epub Apr 18, 2014. http://dx.doi.org/10.1590/S0103-65132014005000021.

DI FELICE, M.; CRISTINA MOREIRA, F. Pachamama e a internet of things: para além da ideia ocidental de cidadania. Lumina, Juiz de Fora, v. 12, n. 3, p. 24-40, dez. 2018. Disponível em: https://periodicos. ufjf.br/index.php/lumina/article/view/21568. Acesso em: 15 mar. 2020.

FERNANDEZ, C.; MACHADO, E.; ROSA, E. 0 Brasil que lê: bibliotecas comunitárias e resistência cultural na formação de leitores. Olinda: Centro de Cultura Luiz Freire; Rede Nacional de Bibliotecas Comunitárias, 2018. 200p. Ebook. Disponível em: http://cclf.org.br/wp-content/uploads/2019/10/ Ebook-OBrasilquele-1.pdf. Acesso em: 17 abr. 2020.

FRANKLIN, B. L. O laboratório invertido: a distribuição do poder computacional como descentração da experiência laboratorial. Liinc em Revista, Rio de Janeiro, v. 13, n. 1, 2017. Disponível em: http:// revista.ibict.br/liinc/article/view/3750. Acesso em: 21 jun. 2019.

FRANKLIN, B. L. Bibliotecas digitais clandestinas: evidenciando a formação de comunidades discursivas na deep web. In: ENCONTRO NACIONAL DE PESQUISA EM CIÊNCIA DA INFORMAÇÃO (ENANCIB), 20., 2019. Anais eletrônicos ... Florianópolis: ANCIB, 2019. Disponível em: https://conferencias.ufsc.br/index.php/enancib/2019/paper/ view/640?fbclid=IwAR1tZykHSs6MqsQ9Re2TAIEvIBww2WF8Ku_zmK4Ra_hIE0MTN9eVg7CW1us. Acesso em: 17 abr. 2020

FUCCI, C. D. Os direitos autorais das obras de artes plásticas e a reprodutibilidade técnica: 0 status fático brasileiro das esculturas. Revista da EMARF, Rio de Janeiro, v. 27, n. 1, p. 1-406, nov. 2017/ abr. 2018. Disponível em: http://seer.trf2.jus.br:81/emarf/ojs/index.php/emarf/article/view/73/87. Acesso em: 21 mar. 2020.

FUNDAÇÃO GETÚLIO VARGAS. Direitos autorais em reforma. Botafogo, RJ: Fundação Getúlio Vargas, 2011.

GEHL, R. W. Weaving the dark web: legitimacy on Freenet, Tor, and I2P, The information society series. Cambridge, Massachusetts: The MIT Press, 2018.

HEIDEGGER, M.; MORUJÃO, C. Que é uma coisa? doutrina de Kant dos princípios transcendentais. Lisboa: Edições 70, 2002.

HESSEN, Johannes; MONCADA, Luís Cabral de. Filosofia dos valores. Coimbra: Almedina, 2001.

HENRIQUES, João. Os REA e o software livre. REAeduca: Revista de Educação para o Século XXI, n. 3, p. 1-8, 2017. 
IBGE. Pesquisa Nacional por Amostra de Domicílios Contínua - Tecnologia da Informação e Comunicação, 2020. Disponível em: https://www.ibge.gov.br/estatisticas/sociais/trabalho/17270pnad-continua.html. Acesso em: 21 maio 2020.

IMPERATORE, S. L. B.; PEDDE, V.; IMPERATORE, J. L. R. Curricularizar a extensão ou extensionalizar o currículo? aportes teóricos e práticas de integração curricular da extensão ante a estratégia do PNE. In: COLÓQUIO INTERNACIONAL DE GESTÃO

UNIVERSITÁRIA (CIGU), 15., 2015. Anais eletrônicos [...] Desafios da Gestão Universitária no Século XXI, Mar del Plata, 2015. Disponível em: https://repositorio.ufsc.br/ handle/123456789/136064. Acesso em: 11 mar. 2020.

JESUS, D. L. de; CUNHA, M. B. da. A biblioteca do futuro: um olhar em direção ao presente. Informação \& Informação, v. 24, n. 3, p. 311-334, 2019. Disponível em: http://www.uel.br/revistas/ uel/index.php/informacao/article/view/38022. Acesso em: 22 mar. 2020.

KINSELLA, N. S. Contra a propriedade intelectual. São Paulo: Instituto Ludwig von Mises Brasil, 2010.

LONGO, L.; SAKATA, N. A. B. Custo Total de Propriedade (Total Cost Ownership) para Decisões de Investimentos em Tecnologia de Informação (TI). Revista Capital Científico - Eletrônica (RCC $ヌ)$, v. 16, n. 1, p. 20-35, 2018. Disponível em: https://revistas.unicentro.br/index.php/capitalcientifico/ article/view/4867. Acesso em: 18 mar. 2020.

MAKHLOUF, R. Cloudy transaction costs: a dive into cloud computing economics. Journal of Cloud Computing, v. 9, n. 1, p. 1, 2020. Disponível em: https://link.springer.com/article/10.1186/s13677019-0149-4. Acesso em: 14 mar. 2020.

MARTINS FILHO, P. Direitos autorais na Internet. Ciência da Informação, Brasília, v. 27, n. 2, 1998. Disponível em: http://www.scielo.br/scielo.php?script=sci_arttext\&pid=S0100$19651998000200011 \& \mathrm{Ing}=\mathrm{en \& nrm}=$ iso. Acesso em: 24 mar. 2020.

M00DY, G. The rebel code: the inside story of Linux and the open source revolution. Cambridge, Mass: Perseus Pub, 2002.

MORENO-LEÓN, Jesús; ROMÁN-GONZÁLEZ, Marcos; ROBLES, Gregorio. On computational thinking as a universal skill: A review of the latest research on this ability. In: 2018 IEEE Global Engineering Education Conference (EDUCON). [s.l.: s.n.], 2018, p. 1684-1689.

ORIÁ, R. Bibliotecas Escolares no Brasil: uma análise da aplicação da Lei nº 12.244/2010. In: Biblioteca Digital da Câmara dos Deputados. Brasília: Câmara dos Deputados, 2017, p. 14.

PIMENTEL, L. 0.; SILVA, C. E. R. de F. Conceito Jurídico de Software, Padrão Proprietário e Livre: Políticas Públicas. Sequência: Estudos Jurídicos e Políticos, Florianópolis, v. 35, n. 68, p. 291329, jun. 2014. Disponível em: https://periodicos.ufsc.br/index.php/sequencia/article/view/21777055.2013v35n68p291. Acesso em: 27 mar. 2020. 
REINSEL, D.; GANTZ, J.; RYDNING, J. The Digitization of the World from Edge to Core. p. 28, 2018. Disponível em: https://www.seagate.com/files/www-content/our-story/trends/files/idc-seagatedataage-whitepaper.pdf. Acesso em: 09 de fev. 2020.

RIFKIN, J. The zero marginal cost society: the internet of things, the collaborative commons, and the eclipse of capitalism. New York: Palgrave Macmillan, 2014.

ROBBINS, L. An essay on the nature and significance of economic science. Local: Macmillan, 1932.

SILVA, S. B. A emergência dos livings labs no Brasil como um meio para a promoção da inovação social. In: Seminário de Ciências Sociais Aplicadas, vol. 3, n. 3, 2012. Disponível em: http:// periodicos.unesc.net/index.php/seminariocsa/article/view/653. Acesso em: 18 jul. 2014.

SILVA, J. L. C. Lei de universalização das bibliotecas escolares (12.244/10): concepções, aplicações e proposição de política pública. Revista Informação Em Cultura, v. 1, n. 1, p. 60-93, 2019. Disponível em: https://doi.org/10.21708/issn2674-6549.v1i1a8521.2019. Acesso em: 20 mar. 2020.

SIMON, I.; VIEIRA, M. S. 0 rossio não-rival. In: SIMON, I.; VIEIRA, M. S. (ed.). Além das redes de colaboração: internet, diversidade cultural e tecnologias do poder. Salvador: UFBA, 2008. p. 15-30.

TEDRE, M.; DENNING, P. J. The long quest for computational thinking. In: Proceedings of the 16th Koli Calling International Conference on Computing Education Research. Koli, Finland: Association for Computing Machinery, 2016, p. 120-129. (Koli Calling '16). Disponível em: https:// doi.org/10.1145/2999541.2999542. Acesso em: 19 mar. 2020.

TORRES, A. L. A tecnoutopia do software livre: uma história do projeto técnico e político do GNU. 2013. Dissertação (Mestrado em História Social) - Faculdade de Filosofia, Letras e Ciências Humanas, Universidade de São Paulo, São Paulo, 2013. Disponível em: https://www.teses.usp.br/teses/ disponiveis/8/8138/tde-31032014-111738/pt-br.php. Acesso em: 18 mar. 2020.

W00D, J. The Darknet: A digital copyright revolution. Richmond Journal of Law and Technology, v. 16, n. 4, p. 15-17, 2011.

ZUBOFF, S. The age of surveillance capitalism: the fight for a human future at the new frontier of power. New York: Public Affairs, 2018. 